\title{
Akt is transferred to the nucleus of cells treated with apoptin, and it participates in apoptin-induced cell death
}

\author{
S. Maddika*, + G. H. Bay*, T. J. Kroczak*, S. R. Ande* + , S. Maddika*, \\ E. Wiechec*,§, S. B. Gibson*,† and M. Los*,†,\$,\# \\ * Manitoba Institute of Cell Biology, Cancer Care Manitoba, $\dagger$ Manitoba Institute of Child Health, †Department of \\ Biochemistry and Medical Genetics, \$Department of Human Anatomy and Cell Science, University Manitoba, Winnipeg, \\ Canada, §Department of Experimental and Clinical Radiobiology, Oncology Center, Maria Sklodowka-Curie Memorial \\ Institute, Gliwice, Poland, ๆDepartment of Human Genetics, University of Aarhus, Aarhus, Denmark, and \\ \#BioApplications Enterprises, Winnipeg, MB, Canada
}

Received 5 May 2007; revision accepted 29 May 2007

\begin{abstract}
Objectives: The phosphatidylinositol 3-kinase (PI3-K)/Akt pathway is well known for the regulation of cell survival, proliferation, and some metabolic routes. Meterials and Methods: In this study, we document a novel role for the PI3-K/Akt pathway during cell death induced by apoptin, a tumour-selective inducer of apoptosis. Results: We show for the first time that apoptin interacts with the p85 regulatory subunit, leading to constitutive activation of PI3-K. The inhibition of PI3-K activation either by chemical inhibitors or by genetic approaches severely impairs cell death induced by apoptin. Downstream of PI3-K, Akt is activated and translocated to the nucleus together with apoptin. Direct interaction between apoptin and Akt is documented. Co-expression of nuclear Akt significantly potentiates cell death induced by apoptin. Thus, apoptin-facilitated nuclear Akt, in contrast to when in its cytoplasmic pool, appears to be a positive regulator, rather than repressor of apoptosis. Conclusions: Our observations indicate that PI3-K/Akt pathways have a dual role in both survival and cell death processes depending on the stimulus. Nuclear Akt acts as apoptosis stimulator rather than as a repressor, as it likely gains access to a new set of substrates in the nucleus. The implicated link between survival and cell death pathways during apoptosis opens new pharmacological opportunities to modulate apoptosis in cancer, for example through the manipulation of Akt's cellular localization.
\end{abstract}

\section{INTRODUCTION}

The phosphatidylinositol 3-kinase (PI3-K) is a lipid kinase that catalyses phosphorylation of the inositol ring of phosphoinositides [PI, PI(4)P and phosphatidylinositol (4,5)-bisphosphate $\left.\left(\mathrm{PI}(4,5) \mathrm{P}_{2}\right)\right]$ at the $\mathrm{D} 3$ position (Fruman et al. 1999; Rameh \& Cantley 1999). Three classes of PI3-K have been identified which differ in their primary structure, regulation and substrate 
specificity (reviewed in Vanhaesebroeck \& Waterfield 1999). Class I PI3-Ks have been the major focus of PI3-K studies and are heterodimers composed of a catalytic subunit (p110) and a regulatory subunit (p85). Interaction of the $\mathrm{nSH} 2$ domain with the tyrosine-phosphorylated proteins is universally accepted to be responsible for PI3-K activation, but there are other studies that report activation of PI3-K via alternative mechanisms. For example, the conformational switch within the p85-p110 holoenzyme can also occur via interactions of SH3 domain/proline rich sequences, BCR-homology domain/GTP-loaded adaptor proteins and others (Liu et al. 1993; Prasad et al. 1993; Pleiman et al. 1994; Zheng et al. 1994).

$\mathrm{Akt} / \mathrm{PKB}$, a serine/threonine kinase, is a crucial kinase downstream of the PDK1 recruitment to the phosphatidylinositol $(3,4,5)$-trisphosphate $\left[\operatorname{Ptd} \operatorname{Ins}(3,4,5) \mathrm{P}_{3}\right]$ lipid messenger, produced via PI3-K activation (Marte \& Downward 1997). Activated Akt modulates the function of numerous substrates related to the regulation of cell proliferation, such as glycogen synthase kinase-3 (GSK-3), cyclin-dependent kinase inhibitors, p2 $1^{\text {Cip1/Waf1 }}$, p27 $7^{\text {kip1 }}$, and mammalian target of rapamycin (mTOR) (Fruman et al. 1998; Song et al. 2005). Another important function of activated PI3-K/Akt in cells is maintaining cell survival by inhibition of apoptosis. The targets of Akt during this process include Bad phosphorylation (a pro-apoptotic Bcl-2 family member), FKHRL1 inactivation (a transcription factor for FasL and Bim) and nuclear factor kappa B activation (Coffer et al. 1998; Vanhaesebroeck \& Alessi 2000).

Apoptin is a $14-\mathrm{kDa}$ protein derived from the chicken anaemia virus. Apoptin selectively induces apoptosis in cancer cells but not in non-malignant cells (reviewed in Alvisi et al. 2006; Maddika et al. 2006); in these, apoptin remains in the cytoplasm, while in transformed cells it migrates into the nucleus and ultimately kills the cell by activation of the mitochondrial death pathway, in a Nur77-dependent manner, independently of death receptors (Los et al. 1995b; Danen-Van Oorschot et al. 2003; Maddika et al. 2005; Poon et al. 2005b). However, targeted translocation of apoptin into the nuclei of normal cells is not sufficient for apoptin's toxicity. Thus, additional interaction partners or specific activation of other signalling pathways in cancer cells, preceding nuclear accumulation, might be necessary for apoptin's tumour specific toxicity. Nuclear accumulation is linked to phosphorylation of apoptin at the threonine-108 (Thr-108) residue by an as yet unknown kinase (Rohn et al. 2002; Poon et al. 2005a) specifically in cancer cells but not in normal cells. Thus, identifying the pathways responsible for phosphorylation of apoptin might provide clues about its tumour-specific toxicity. These pathways may also represent attractive targets for the development of new highly selective anticancer drugs.

In this study, we have investigated the role of the PI3-K/Akt pathway in apoptin-induced cell death. Our results intriguingly demonstrate that apoptin interacts with the p85 regulatory subunit, which leads to the constitutive activation of PI3-K; inhibition of this activation process severely impairs apoptin-induced cell death. We also demonstrate nuclear translocation of Akt during apoptin-induced cell death. Nuclear translocation of Akt alone does not have a toxic effect, but it strongly potentiates the toxicity of apoptin.

\section{MATERIALS AND METHODS}

\section{Cell culture and reagents}

PC-3 and MCF-7 cells were grown in RPMI-1640 medium supplemented with 10\% foetal bovine serum (Hyclone, Logan, UT, USA), $100 \mu \mathrm{g} / \mathrm{mL}$ penicillin and $0.1 \mu \mathrm{g} / \mathrm{mL}$ streptomycin (Gibco BRL, Grand Island, NY, USA). The cells were grown at $37{ }^{\circ} \mathrm{C}$ with $5 \% \mathrm{CO}_{2}$ in a humidified incubator. Peripheral blood lymphocytes were isolated from chronic lymphocytic leukaemia 
(CLL) patients or from normal healthy individuals, by Ficoll gradient fractionation, as described previously (Los et al. 1995a), and were maintained in RPMI medium. The following antibodies were used: murine anti-PI3-K (p85), antimouse immunoglobulin $\mathrm{G}$ (IgG) horseradish peroxidase (HRP), antirabbit IgG HRP (all from Upstate Cell Signalling, Beverly, MA, USA), goat anti-Akt, murine antitubulin, rabbit anti-GFP, antigoat IgG HRP (all from Santa Cruz Biotechnologies, Santa Cruz, CA, USA), murine antiphospho-Akt Ser-473 (Cell Signalling), antihuman CD5FITC, CD19-PerCP (BD Biosciences, San Jose, CA, USA), antigoat Cy3, antirabbit Cy3 and antimurine $\mathrm{Cy} 3$ (all from Sigma, St. Louis, MO, USA). The following inhibitors were used: wortmannin ( $\mathrm{IC}_{50} 5 \mathrm{nM}$ ), LY294002 ( $\mathrm{IC}_{50} 1.4 \mu \mathrm{M}$ ) (all from Calbiochem, San Diego, CA, USA).

\section{B-cell staining and FACS analysis}

Peripheral blood lymphocytes from normal individuals and CLL patients either left untreated or TAT-apoptin treated for the indicated times were washed twice with ice-cold phosphate-buffered saline (PBS), and then were incubated (individually) with both CD5-FITC and CD19-PerCP antibodies (each $0.5 \mu \mathrm{g}$ per $10^{6}$ cells) for $30 \mathrm{~min}$ at $4{ }^{\circ} \mathrm{C}$ in dark. The cells were then washed twice with ice-cold PBS and were re-suspended in $300 \mu \mathrm{L}$ of PBS. Samples were analysed by flow cytometry by using both FL1 (FITC) and FL2 (PerCP) channels, and percentage of B cells obtained by gating the double positive cells compared to unstained controls.

\section{Protein purification, GST pull-down assay and protein identification}

The TAT-GFP and TAT-apoptin proteins were purified as previously described (Maddika et al. 2005). Glutathione S-transferase (GST) and GST-apoptin were purified by using glutathione-Sepharose high-performance beads (Amersham Biosciences, Piscataway, NJ, USA) according to the manufacturer's protocol. The GST pull-down assay was performed to detect apoptin's interacting partners. Briefly, either purified GST or GST-apoptin along with total PC-3 cell lysate was immobilized on glutathione-Sepharose beads overnight at $4{ }^{\circ} \mathrm{C}$. The beads were washed three times with ice-cold lysis buffer and bound proteins were isolated on sodium dodecyl sulfatepolyacrylamide gel electrophoresis. Proteins specific for apoptin were subjected to in-gel digestion and were further identified by matrix-assisted laser desorption/ionization time-of-flight mass spectrometry, at the proteomics centre of the University of Manitoba, Manitoba, Canada. Finally, proteins from the GST pull-down assay were identified by immunoblotting.

\section{Plasmids, transfections and adenoviral infections}

The following plasmid were used: GFP-apoptin (apoptin cloned into pEGFP-C1 vector, clonetech), GST-apoptin (apoptin cloned into PGEX-2T vector, Amersham Biosciences), PI3-K dominantnegative vector, Akt wild-type vector [J. Downward, UK (Kauffmann-Zeh et al. 1997)], PDK1 dominant-negative and constitutively active vectors (A. Halayko, Winnipeg, Manitoba, Canada), phosphatase and Tensin homolog (PTEN) wild-type and PTEN C124S phosphatase-dead mutant (D. H. Anderson, Saskatchewan Cancer Agency, Saskatchewan, Canada), Ad-NLS-Akt [M. A. Sussman, San Diego, CA, USA (Shiraishi et al. 2004), and Ad-Akt dominant-negative vector K. Walsh (Luo et al. 2000)]. Transfection was performed using Lipofectamine (Invitrogen, Burlington, ON, Canada) according to the manufacturer's recommendations. Adenoviral transfections with Akt dominant-negative mutant vector and nuclear-targeted Akt were performed as previously described (Fujio et al. 1999).

\section{PI3-K ELISA}

A non-radioactive competitive ELISA-based assay was used to assess the PI3-K activity, according to the manufacturer's protocol (Echleon Biosciences, Salt Lake City, UT, USA). Briefly, 
equal amounts of PI3-K from the PC-3 cell lysates were immuno-precipitated with anti-p85 antibodies overnight at $4{ }^{\circ} \mathrm{C}$ and then were incubated with protein A-Sepharose beads for $1 \mathrm{~h}$ at $4{ }^{\circ} \mathrm{C}$. Bead-bound enzymes were incubated with $100 \mathrm{pm}$ of $\mathrm{PI}(4,5) \mathrm{P}_{2}$ substrate in kinase reaction buffer (4 mM $\mathrm{MgCl}_{2}, 20 \mathrm{~mm}$ Tris, $\mathrm{pH} 7.4,10 \mathrm{~mm} \mathrm{NaCl}$ and $25 \mu \mathrm{M}$ ATP) for $2 \mathrm{~h}$ at room temperature. The mixtures were then incubated with $\mathrm{PI}(3,4,5) \mathrm{P}_{3}$ detector for $1 \mathrm{~h}$ at room temperature in the dark, subsequently were added to $\mathrm{PI}(3,4,5) \mathrm{P}_{3}$-coated microplate wells and were incubated for $30 \mathrm{~min}$ at room temperature in the dark. After thorough washing, peroxidase-linked secondary detection reagent was added, and $\mathrm{PI}(3,4,5) \mathrm{P}_{3}$ detector protein binding to the plate was assessed by measuring absorbance at $450 \mathrm{~nm}$. Data for the kinase activity are expressed as fold induction in transfected cells compared to the activity in untreated cells.

\section{Immuno-precipitation and immunoblotting}

Cells were washed twice with ice-cold PBS, lysed with ice-cold lysis buffer (50 mm Tris, pH 7.5, $1 \%$ Nonidet P-40, $150 \mathrm{~mm} \mathrm{NaCl}, 1 \mathrm{~mm} \mathrm{Na}_{3} \mathrm{VO}_{4}, 2$ mM EGTA, Protease inhibitor cocktail), were incubated for $10 \mathrm{~min}$ on ice, and then were centrifuged for $10 \mathrm{~min}$ at $4{ }^{\circ} \mathrm{C}$. Immuno-precipitations were performed with the indicated antibodies (Fig. 1c) and the immuno-complexes were captured with protein A-agarose beads (Amersham Pharmacia Biotech). After three washing steps with cell lysis buffer, bead-bound proteins were subjected to Western blot analysis as described previously (Maddika et al. 2005). When appropriate, quantification of Western blot data was performed using the ImageQuant 5.2 software (Molecular Dynamics, Sunnyvale, CA, USA).

\section{Immunolocalization studies}

PC-3 cells were transfected to express apoptin and were fixed $24 \mathrm{~h}$ later in $4 \%$ paraformaldehyde in PBS, permeabilized in $0.2 \%$ Triton X-100 and were stained with either anti-p 85 or anti-Akt antibodies followed by their respective appropriate secondary antibodies, conjugated to Cy3. The fluorescent images were analysed by confocal microscopy.

\section{Statistical analysis}

Statistical significance of the data was confirmed using Student's $t$-test.

\section{Apoptosis and cell death assays}

The measurement of apoptosis was performed using the Nicoletti method followed by flow cytometry, as previously described (Maddika et al. 2005). Cell death was quantitatively confirmed by the microtiter tetrazolium (MTT) assay as previously described (Ghavami et al. 2005).

\section{RESULTS}

\section{Apoptin selectively kills cancer cells dependent on the PI3-K pathway}

First, we re-assessed the cancer cell-selective toxicity of apoptin, a controversial question in apoptin biology, using peripheral blood lymphocytes (PBLs) from CLL patients compared to peripheral blood lymphocytes from a normal healthy individual. B cells in CLL and normal PBLs were detected by double staining for the specific surface markers CD5 and CD19. In normal PBLs, there was no significant difference in the B-cell population before $(6.1 \%)$ or after $(5.2 \%) 48 \mathrm{~h}$ of treatment with TAT-apoptin. In contrast, there was a significant decrease in the CLL PBLs upon TAT-apoptin treatment (11.2\%) compared to the control (40.1\%) (Fig. 1a). Thus, the data indicate that apoptin effectively kills malignant B cells from CLL patients, but 

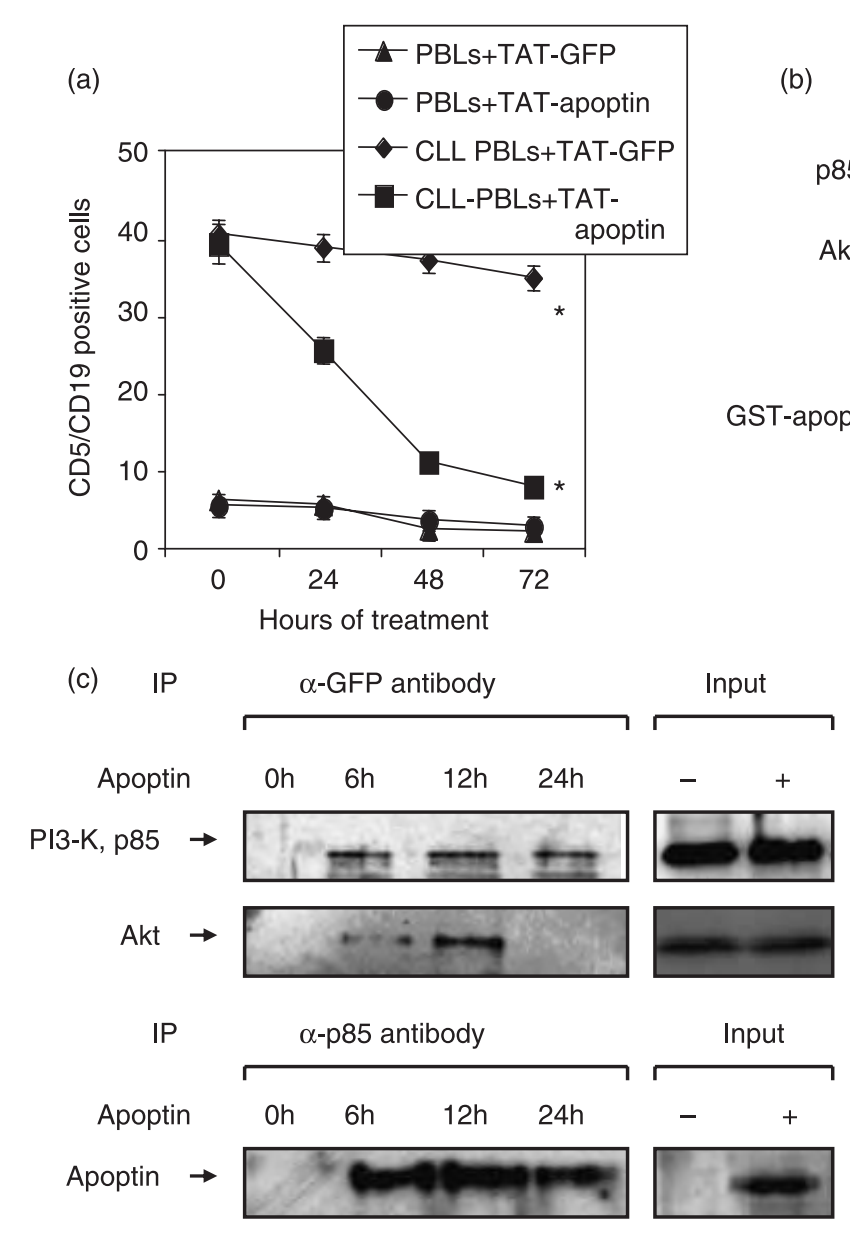

(b)
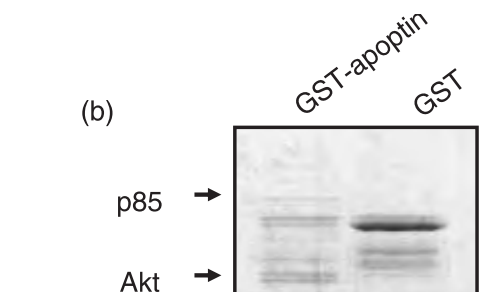

GST-apoptin -

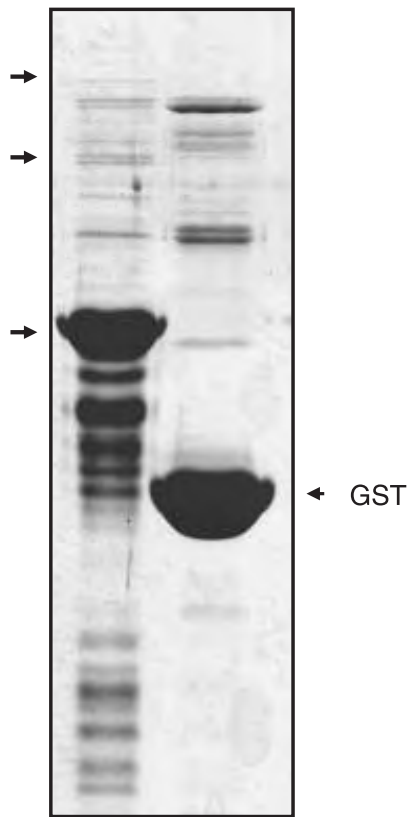

Input

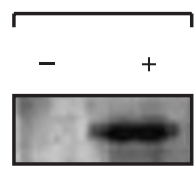

IP

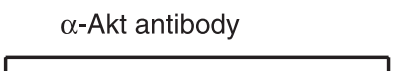

Input

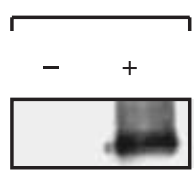

Figure 1. Apoptin selectively kills cancer cells by interacting with the PI3-kinase (p85 subunit) and Akt. (a) B cells from either normal peripheral blood lymphocytes (PBLs) or the chronic lymphocytic leukaemia PBLs were double stained for CD5/CD19 surface markers using FITC-conjugated CD5 and Per-CP-conjugated CD19 antibodies, at different time points after either TAT-GFP or TAT-apoptin treatment. The samples were then analysed by flow cytometry and numbers of CD5/CD19 double-positive cells were plotted. The data are statistically significant $(* P<0.02)$ as measured by Student's $t$-test. (b) GST pull-down assay performed with PC-3 cell lysate using either GST control or GST-apoptin and the proteins (p85, PI3-K and Akt) specific for apoptin interaction identified by mass spectrometry are indicated. (c) Co-immuno-precipitation indicates the interaction of apoptin with p85 and Akt. PC-3 cell lysates were immunoprecipitated with anti-GFP antibody (GFP-apoptin) at different time points, upon transfection with GFP-apoptin. Co-immuno-precipitated p85 and Akt were detected by Western blot analysis. Reciprocal immuno-precipitation with either anti-p85 or anti-Akt antibodies, and detection of apoptin by immunoblotting is shown at the bottom. 
not the normal counterparts, therefore confirming apoptin's selective toxicity (Fig. 1a). TAT-GFP, used as a negative control for this toxicity, had no significant effect on the survival of either normal or malignant cells.

As a first step to identify cellular targets of apoptin action in the cell, we generated an expression construct encoding GST fused to the apoptin N-terminus. GST-apoptin and control GST were used in a pull-down assay with cell extracts derived from the PC-3 prostate cancer cells (Fig. 1b). Mass spectrometric analysis of proteins specifically bound to apoptin identified the two major components of the PI3-K/Akt pathway the p85 regulatory subunit of PI3-K, and the serine/threonine kinase Akt, a kinase downstream of PI3-K. We also found that apoptin interacts with proteins such as chaperones, actin and tubulin family members (data not shown), as observed previously (Teodoro et al. 2004). Interaction of apoptin with PI3-K and Akt was also examined in vivo, whereby PC-3 cells were transfected with GFP-apoptin, and total cell extracts immuno-precipitated with anti-GFP antibody at different time points, post-transfection, and composition of the immune complexes was analysed for PI3-K and Akt by immunoblotting. In a separate series of experiments, PI3-K (p85) and Akt were immuno-precipitated, and apoptin detected by Western blot analysis. Figure 1c shows that PI3-K and Akt both interact with apoptin confirming the data from Fig. 1b. Interaction of apoptin with PI3-K could be detected $6 \mathrm{~h}$ after apoptin transfection, thus preceding apoptin-induced cell death, which was initiated at least 18$24 \mathrm{~h}$ later. The above experiment indicates that PI3-K interaction with apoptin is a very early event in apoptin-induced cell death. As shown in Fig. 1c, apoptin strongly interacts with PI3-K within 6-24 h post-transfection. In some further experiments, the interaction could be observed much longer - for over $48 \mathrm{~h}$. On the contrary, the interaction of apoptin with Akt seems weaker and is seen only at certain time points after apoptin treatment.

\section{PI3-K is constitutively activated during apoptin-induced apoptosis}

To determine the functional significance of apoptin's interaction with the $\mathrm{p} 85$ regulatory subunit, we measured PI3-K activity using a non-radioactive ELISA-based method. Surprisingly, MCF-7 and PC-3 cells transfected to express GFP-apoptin revealed constitutive activation of PI3-K in apoptin-transfected cells (Fig. 2a). PI3-K activity was increased nearly 4-fold in apoptin-treated MCF-7 cells and up to 6-fold in PC-3 cells, compared to the GFP-transfected control. PI3-K activation was seen around $6 \mathrm{~h}$ after transfection, consistent with the interaction data (Fig. 1b,c), with activation retained at a similar level for up to a further $40 \mathrm{~h}$. To support the positive role of PI3-K/Akt pathway and to investigate the direct effect of PI3-K inhibition on apoptin-induced cell death, we pretreated the cells with the PI3-K inhibitors, wortmannin and LY294002, 30 min before transfection to express apoptin, and cell death was assayed 24 and $48 \mathrm{~h}$ later. To our surprise, both inhibitors afforded significant protection against apoptin-induced cell death, despite generally being known to enhance the cell death process through inhibition of PI3-K activity (Fig. 2b). This effect was further confirmed by co-transfection of cells to express apoptin together with a dominant-negative derivative of PI3-K, which significantly protected cells from apoptin-induced cell death (Fig. 2b).

\section{Akt is activated downstream of PI3-K during apoptin-induced cell death}

We next investigated the effect of apoptin on downstream targets of the PI3-K pathway by transfecting the PC-3 cells to express apoptin, and assessing Akt activation by Western blotting at different time points post-transfection. In agreement with the results for PI3-K activation, increased levels of activated Akt were seen around 6-12 h post-transfection, with pronounced levels of phosphorylated Akt detectable even up to $24 \mathrm{~h}$ post-transfection (Fig. 3a). Activation of Akt is downstream of, and is dependent on PI3-K activation; pre-treatment of cells with the inhibitors 

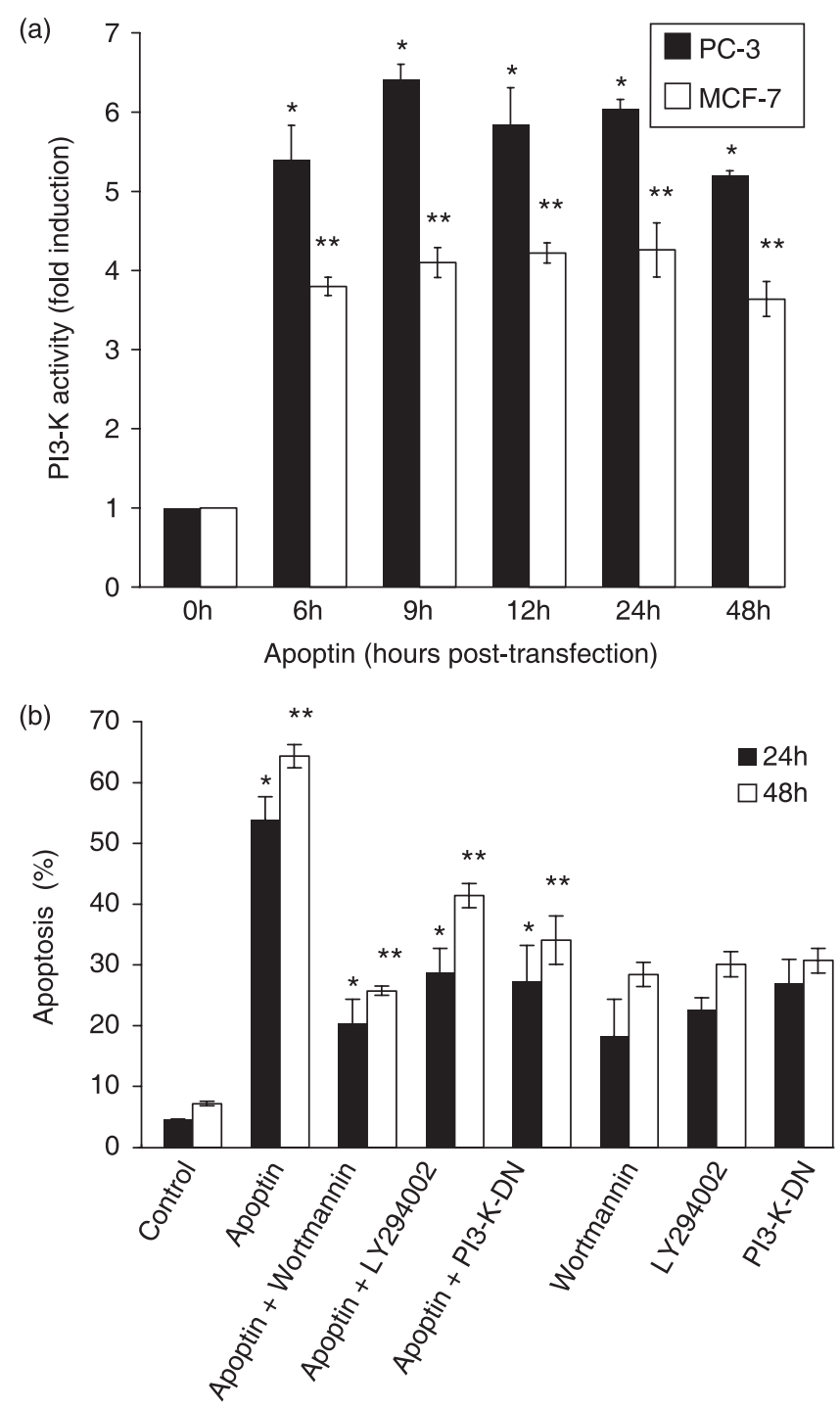

Figure 2. PI3-K is constitutively activated during apoptin-induced apoptosis. (a) PI3-K activity was measured by an ELISA-based assay after immuno-precipitating PI3-K from the lysates of PC-3 and MCF-7 cells, transfected to express apoptin (time points indicate time post-transfection) as described in the methods section, and the fold induction was calculated. PI3-K activity in non-transfected cells was considered as a basal level (1x). Significance of the data was statistically confirmed $\left(* P<0.02\right.$ and $\left.{ }^{*} * P<0.04\right)$ using Student's $t$-test. (b) The effect of PI3-K inhibition on apoptininduced cell death was assessed by flow cytometry (Nicoletti method). Cells were either transfected to express GFP (control) or GFP-apoptin, in the absence or presence of treatment with wortmannin or LY294002, or transfection to coexpress the dominant-negative PI3-K (PI3-K-DN). Apoptosis was then measured 24 and $48 \mathrm{~h}$ post-transfection, with results compared to those for control treatments of wortmannin or LY294002 alone, or PI3-K-DN expression alone. The data are statistically significant $(* P<0.02$ and $* * P<0.03)$ as revealed by Student's $t$-test. 
(a)

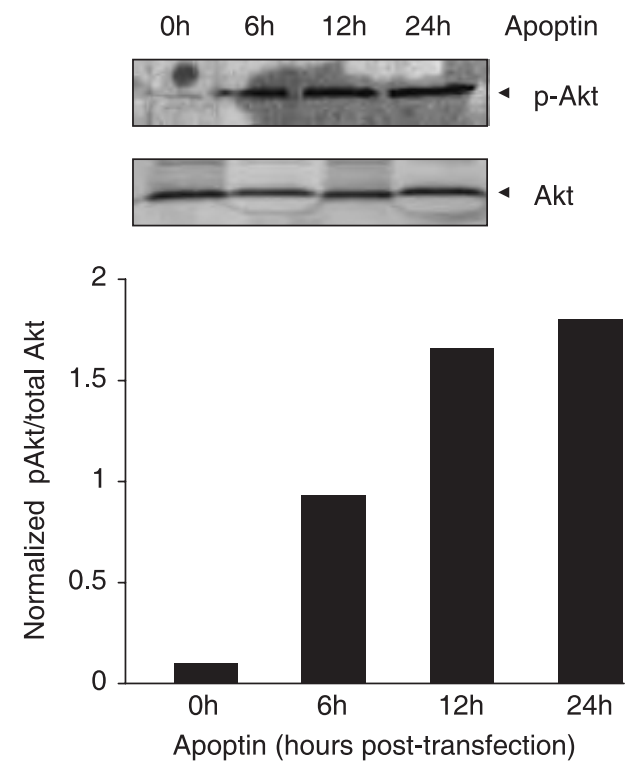

(c)
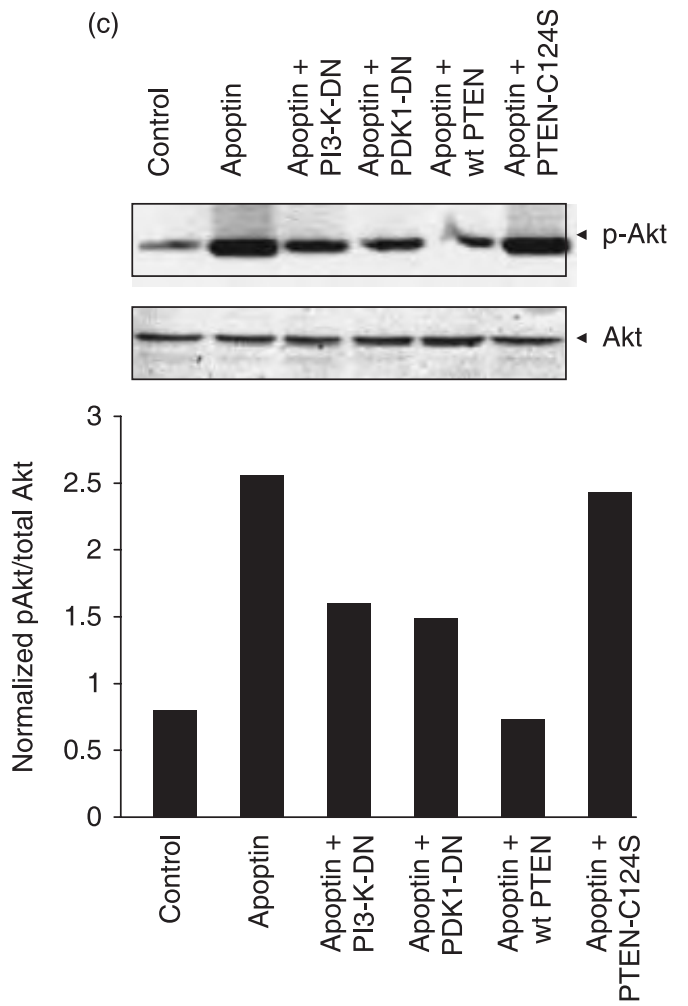

(b)
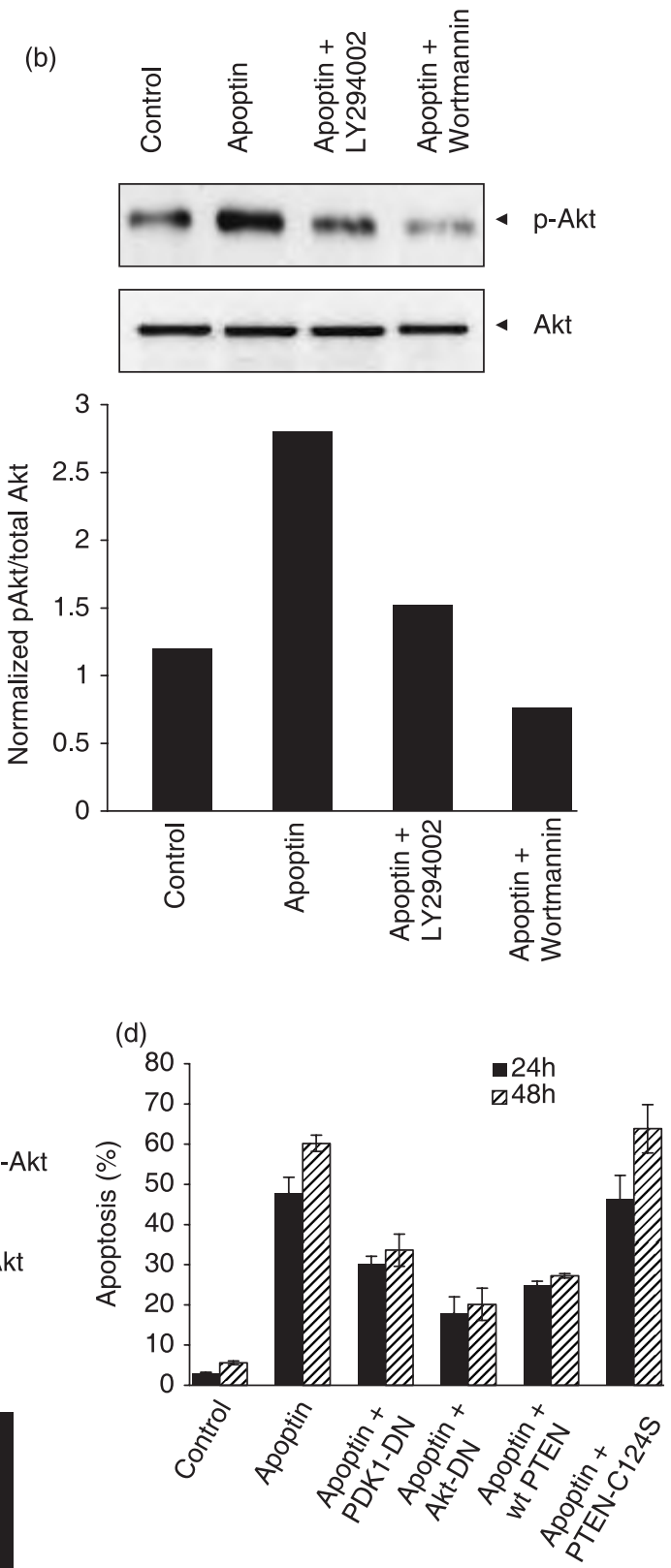
wortmannin or LY294002 (Fig. 3b), or cotransfection of apoptin-expressing cells with constructs encoding PI3-K or PDK1 dominant-negative mutants, impaired Akt activation. Furthermore, overexpression of wild-type PTEN, a negative regulator of Akt activation, severely reduced apoptin-induced Akt activation, while overexpression of a phosphatase-deficient PTEN mutant had no effect (Fig. 3c). No effect was seen on total Akt levels by any of these treatments (data not shown). To further confirm the role of PI3-K in apoptin-induced cell death, and to validate the role of Akt in this process, we transiently overexpressed a dominant-negative mutant of PDK1 (PDK1-DN), and/or the dominant-negative Akt (Akt-DN) using adenoviral vectors. Both dominant-negative kinase mutants as well as overexpression of wild-type PTEN significantly protected against apoptin-induced cell death, thus confirming the key role of the PI3-K/Akt pathway in this process (Fig. 3d).

\section{Akt translocates to the nucleus during apoptin-induced cell death}

Akt is generally regarded as a survival or proliferation-promoting kinase and not as a pro-apoptotic factor. However, in the presence of apoptin, Akt is clearly acting as a pro-cell death molecule as its inhibition severely inhibits cell death pathways triggered by apoptin. Next, we asked if apoptin redirects Akt to different cellular targets by modulating its subcellular localization. As shown in Fig. 4a, Akt is mainly localized in the cytoplasm of untransfected PC-3 cells in the absence of apoptin expression, but is clearly nuclear in its presence. Analysis of the kinetics of Akt nuclear translocation revealed that most of the cytoplasmic Akt translocates to the nucleus within $12 \mathrm{~h}$ of transfection to express apoptin (data not shown). To determine whether nuclear Akt alone is sufficient to induce cell death, even in the absence of an apoptotic stimulus, we infected PC-3 cells with a nuclear localization signal (NLS)-Akt adenoviral vector in the absence and in the presence of apoptin expression. Quantitative analysis using flow cytometry, to determine the extent of cell death (Fig. 4b), indicated that NLS-Akt after $48 \mathrm{~h}$ of transduction, exhibits slightly increased toxicity (13\%) compared to the negative (wild-type) control (7\%). Importantly, co-expression of NLS-Akt together with apoptin sensitized the cells towards apoptin-induced cell death at 24 and $48 \mathrm{~h}$ after apoptin transfection. Together, the data indicate that nuclear Akt alone may not be sufficient for cell death induction, but can clearly facilitate cell death in the presence of certain apoptotic stimuli.

\section{DISCUSSION}

In this study, we have investigated for the first time the role of the PI3-K/Akt pathway in cancer cell-selective death, triggered by apoptin. Interestingly, our results show that the PI3-K/Akt

Figure 3. Akt is activated downstream of PI3-K during apoptin-induced cell death. (a) The activation of Akt by apoptin was detected in PC-3 cells by immunoblotting, using an antibody against Akt-phosphorylated at Ser-473 (p-Akt) at different time points after transfection to express apoptin. Total Akt was detected by immunoblotting. Signals for total and phosphorylated Akt were then scanned and evaluated using ImageQuant 5.2 software. Normalized level of phosphorylated Akt is shown in the graph below. (b) PC-3 cells were transfected to express apoptin in the absence or presence of treatment with wortmannin or LY294002, and phosphorylated Akt, was then detected by immunoblotting. The normalized amount of phosphorylated Akt is shown in the graph below. (c) Akt activation was also determined by immunoblotting in lysates from cells transfected to express apoptin alone or apoptin together with either dominant-negative (DN) PI3-K, PDK1-DN, wild-type PTEN, or phosphatase-deficient C124S-PTEN mutant. The normalized amount of phosphorylated Akt is shown in the graph below. The significance of the data was statistically confirmed $(P<0.02)$ using Student's $t$-test. (d) The effect of Akt inhibition on apoptin toxicity was assessed in PC-3 cells by flow cytometry (Nicoletti method), either $24 \mathrm{~h}$ or $48 \mathrm{~h}$ after transfection, to express apoptin either alone or together with PDK1-DN, Akt-DN (adenoviral vector), wild-type PTEN or C124S-PTEN. The results obtained were confirmed using the MTT assay (data not shown). 
(a)
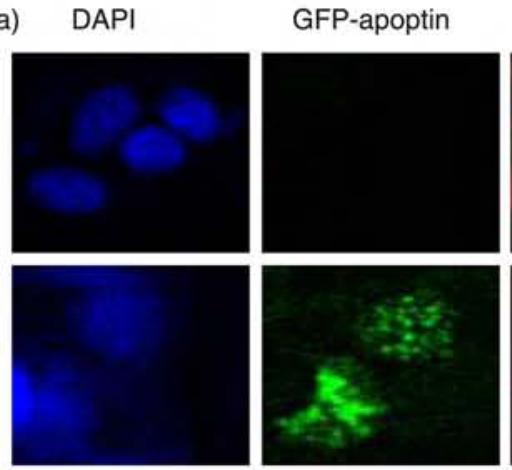

(b)
Akt-Cy3
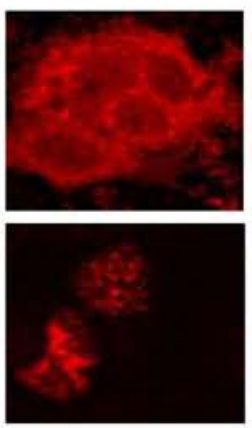

\section{Overlay}

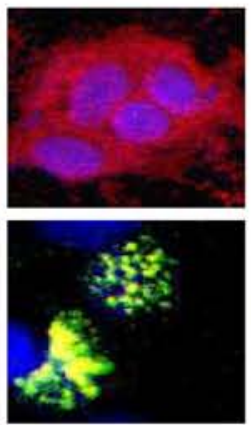

Control

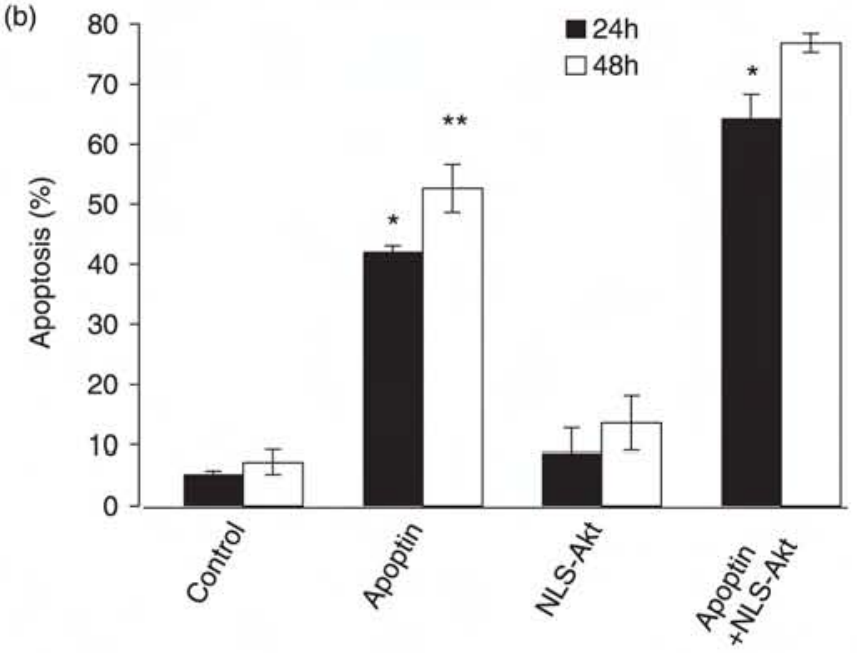

Figure 4. Akt translocates to the nucleus during apoptin-triggered cell death. (a) Localization of Akt either in the absence or in the presence of apoptin in PC-3 cells was detected by confocal microscopy, after immunostaining with anti-Akt antibody followed by Cy3-conjugated secondary antibody. DAPI was used as the nuclear counterstain, and the images were overlaid (right panels). (b) Quantitative assessment of apoptin-triggered apoptosis in NLS-Akt expressing cells, as compared to controls. Cells were infected with adenovirus encoding NLS-Akt, and/or were transfected to express GFP-apoptin. Apoptotic cell death was detected by flow cytometry (Nicoletti method) 24 or $48 \mathrm{~h}$ after transfection. Data represent the average of three independent experiments. Significance of the data was statistically confirmed $\left({ }^{*} P<0.02\right.$ and $\left.{ }^{*} * P<0.025\right)$ using Student's $t$-test. Results obtained were confirmed using the MTT assay (data not shown).

signalling pathway, universally accepted as promoting cell survival and proliferation, can also have a critical role in promoting cell death in response to certain stimuli. Moreover, we demonstrate that the inhibition of PI3-K activation by either pharmacological inhibitors or by genetic methods can abrogate cell death induced by the viral protein apoptin. The apoptin-inhibitory effect of PI3-K inhibitors could be observed, despite their inherent death promoting activity, if used at higher concentrations. Several molecules in the literature have been assigned a dual role in both cell survival and cell death mechanisms. For instance, the oncogene c-myc (Henriksson \& Luscher 1996; Hueber et al. 1997), nuclear factor kappa B (Barkett \& Gilmore 1999), molecules of Ras/Map kinase pathway (Downward 2003; Brown \& Benchimol 2006), Bcl-2 (Cory \& Adams 2002; Subramanian \& Chinnadurai 2003), caspases (Los et al. 2001), cyclins 
A, B, D, E (Maddika et al. 2007) and even an orphan nuclear receptor Nur77 (Lin et al. 2004) are all involved in promoting either cell proliferation or cell death, depending on the context and the stimulus. So far, the PI3-K/Akt pathway has been implicated only in the preferment of cell survival, proliferation, growth, transcription and translation (Cantley 2002). The specific role of the PI3-K/Akt pathway in a pro-cell death pathway has thus far not been clarified.

Although PI3-K is known to be involved in cell survival, several publications have hinted at the fact that active PI3-K may contribute to apoptosis under certain conditions (Aki et al. 2003; Nimbalkar et al. 2003; Maddika et al. 2007). Intriguingly in this context, Akt inhibitors have proved to be only moderately successful in experimental cancer therapy (Stein 2001; Workman 2004). We document here for the first time that activated Akt, if translocated to the nucleus, can stimulate rather than protect against apoptosis induced by cytotoxic stimuli such as administration of apoptin. We hypothesize that in the presence of apoptin, Akt is aberrantly activated and targets cellular substrates and/or pathways in the nucleus that are different from its targets during cell survival mechanisms. Thus, the net outcome of Akt activation could vary according to signalling context, type of stimuli and temporal characteristics of signals that they trigger (e.g. transient versus constitutive signalling). There are well-established examples of such context-dependent, dramatic changes in the final outcome of activation of certain signalling pathways. For example, the proto-oncogene c-myc stimulates cell proliferation in the presence of appropriate survival stimuli (including activated PI3-K/Akt pathway) and triggers apoptosis in their absence (Pelengaris et al. 2002a). This dual capacity ensures that cell growth is restricted to the correct paracrine environment, co-activation of a pro-survival signalling pathway, and/or co-expression of antiapoptotic molecules, and is thereby strictly controlled by multiple mechanisms (Kauffmann-Zeh et al. 1997; Pelengaris et al. 2002b; Baudino et al. 2003).

We have demonstrated that interaction of apoptin with the p85 regulatory subunit constitutively activates PI3-K. In addition to apoptin's interaction with PI3-K, we observed transient interaction with Akt. Furthermore, interaction of Akt with apoptin appears to facilitate Akt nuclear localization. Apoptin thus effects Akt's nuclear translocation, presumably enabling access to pro-apoptotic phosphorylation targets that do not normally come into contact with cytoplasmic Akt. Nuclear access of Akt alone is not sufficient to induce apoptosis, because NLSAkt alone does not induce cell death, but can potentiate apoptin-induced cell death. Recently, Trotman et al. (2006) reported that the promyelocytic leukaemia tumour suppressor prevents cancer by dephosphorylating and inactivating Akt inside the nucleus. Other workers have reported that phosphorylated nuclear, but not cytoplasmic Akt, interacts with Ebp1 (an inhibitor of caspase-activated DNase-dependent apoptotic DNA fragmentation), and enhances its antiapoptotic action independently of Akt kinase activity, in a cell-free experimental system (Ahn et al. 2006). Thus, nuclear Akt contributes to cell death pathways only in the presence of certain apoptotic stimuli, implying that nuclear Akt may have pro-survival and proliferation-promoting function, depending on the experimental conditions.

There are several reported nuclear targets of Akt, including FOXO3a (Brunet et al. 1999), Nur77 (Pekarsky et al. 2001) and p21 cip/waf (Li et al. 2002). We have previously shown that Nur77 translocates from the nucleus to mitochondria during apoptin-induced cell death (Maddika et al. 2005); we still have to define the connection between nuclear Akt and this translocation. We have also observed down-regulation of $\mathrm{p} 21^{\text {cip/waf }}$ (unpublished data) $24 \mathrm{~h}$ after cell death induction by apoptin, although this occurs independently of Akt activation, because Akt inhibition by wortmannin did not affect $\mathrm{p} 21^{\mathrm{cip} / \text { waf }}$ levels. Down-regulation of $\mathrm{p} 21^{\mathrm{cip} / \mathrm{waf}}$ may be the result of cleavage by caspases, as a secondary event, downstream of mitochondrial death pathway activation. Further studies in our laboratory are focused on identifying different nuclear targets of Akt during apoptin-induced cell death. 
Different components of the PI3-K/Akt pathway are involved in tumourigenesis and are highly active in various types of cancer cell compared to normal cells (reviewed in Vivanco \& Sawyers 2002; Luo et al. 2003). Furthermore, PTEN, a phosphatase that counteracts PI3-K's action, is the second most commonly mutated tumour suppressor gene after p53 (Vivanco \& Sawyers 2002). Hyper-activation of the PI3-K/Akt pathway indicates poor clinical prognosis and also contributes to drug resistance during cancer treatment. Thus, apoptin's targeting of these very pathways that are hyperactive in cancer, may explain its unique properties of tumour-specific toxicity. Our data strongly indicate that apoptin hijacks these survival pathways and redirects them from their normal survival/proliferatory action towards the activation of the cell death.

\section{ACKNOWLEDGEMENTS}

T. J. Kroczak has been supported by the Manitoba Institute of Child Health. M. Los thankfully acknowledges the support by the Canada Foundation for Innovation-Canada Research Chairs program, the Prostate Cancer Research Foundation of Canada-, the Canadian Institutes of Health Research (CIHR)-, CIHR Intellectual Property Mobilization-, CCMF- and MHRC-financed programs. We acknowledge the support of CancerCare Manitoba Translational Research program and Manitoba CLL tissue bank.

\section{REFERENCES}

Ahn JY, Liu X, Liu Z, Pereira L, Cheng D, Peng J, Wade PA, Hamburger AW, Ye K (2006) Nuclear Akt associates with PKC-phosphorylated Ebp1, preventing DNA fragmentation by inhibition of caspase-activated DNase. EMBO J. 25, 2083-2095

Aki T, Yamaguchi K, Fujimiya T, Mizukami Y (2003) Phosphoinositide 3-kinase accelerates autophagic cell death during glucose deprivation in the rat cardiomyocyte-derived cell line H9c2. Oncogene 22, 8529-8535.

Alvisi G, Poon IK, Jans DA (2006) Tumor-specific nuclear targeting: promises for anti-cancer therapy? Drug Resist. Updat. 9, 40-50.

Barkett M, Gilmore TD (1999) Control of apoptosis by Rel/NF-kappaB transcription factors. Oncogene 18, 69106924.

Baudino TA, Maclean KH, Brennan J, Parganas E, Yang C, Aslanian A, Lees JA, Sherr CJ, Roussel MF, Cleveland JL (2003) Myc-mediated proliferation and lymphomagenesis, but not apoptosis, are compromised by E2f1 loss. Mol. Cell 11, 905-914.

Brown L, Benchimol S (2006) The involvement of MAPK signaling pathways in determining the cellular response to p53 activation: cell cycle arrest or apoptosis. J. Biol. Chem. 281, 3832-3840.

Brunet A, Bonni A, Zigmond MJ, Lin MZ, Juo P, Hu LS, Anderson MJ, Arden KC, Blenis J, Greenberg ME (1999) Akt promotes cell survival by phosphorylating and inhibiting a Forkhead transcription factor. Cell 96, 857-868.

Cantley LC (2002) The phosphoinositide 3-kinase pathway. Science 296, 1655-1657.

Coffer PJ, Jin J, Woodgett JR (1998) Protein kinase B (c-Akt): a multifunctional mediator of phosphatidylinositol 3-kinase activation. Biochem. J. 335, 1-13.

Cory S, Adams JM (2002) The Bcl2 family: regulators of the cellular life-or-death switch. Nat. Rev. Cancer 2, $647-656$.

Danen-Van Oorschot AA, Zhang YH, Leliveld SR, Rohn JL, Seelen MC, Bolk MW, Van Zon A, Erkeland SJ, Abrahams JP, Mumberg D, Noteborn MH (2003) Importance of nuclear localization of apoptin for tumor-specific induction of apoptosis. J. Biol. Chem. 278, 27729-27736.

Downward J (2003) Targeting RAS signalling pathways in cancer therapy. Nat. Rev. Cancer 3, 11-22.

Fruman DA, Meyers RE, Cantley LC (1998) Phosphoinositide kinases. Annu. Rev. Biochem. 67, 481-507.

Fruman DA, Rameh LE, Cantley LC (1999) Phosphoinositide binding domains: embracing 3-phosphate. Cell 97, 817820. 
Fujio Y, Guo K, Mano T, Mitsuuchi Y, Testa JR, Walsh K (1999) Cell cycle withdrawal promotes myogenic induction of Akt, a positive modulator of myocyte survival. Mol. Cell. Biol. 19, 5073-5082.

Ghavami S, Barczyk K, Maddika S, Vogl T, Steinmüller L, Pour- Jafari H, Evans JA, Los M (2005) Monitoring of programmed cell death in vivo and in vitro - new and old methods of cancer therapy assessment. In: Los M, Gibson SB, eds. Apoptotic Pathways as Target for Novel Therapies in Cancer and Other Diseases. New York: Springer Academic Press, pp. 323-341.

Henriksson M, Luscher B (1996) Proteins of the Myc network: essential regulators of cell growth and differentiation. Adv. Cancer Res. 68, 109-182.

Hueber AO, Zornig M, Lyon D, Suda T, Nagata S, Evan GI (1997) Requirement for the CD95 receptor-ligand pathway in c-Myc-induced apoptosis. Science 278, 1305-1309.

Kauffmann-Zeh A, Rodriguez-Viciana P, Ulrich E, Gilbert C, Coffer P, Downward J, Evan G (1997) Suppression of c-Myc-induced apoptosis by Ras signalling through PI (3) K and PKB. Nature 385, 544-548.

Li Y, Dowbenko D, Lasky LA (2002) AKT/PKB phosphorylation of p21Cip/WAF1 enhances protein stability of p21Cip/ WAF1 and promotes cell survival. J. Biol. Chem. 277, 11352-11361.

Lin B, Kolluri SK, Lin F, Liu W, Han YH, Cao X, Dawson MI, Reed JC, Zhang XK (2004) Conversion of Bcl-2 from protector to killer by interaction with nuclear orphan receptor Nur77/TR3. Cell 116, 527-540.

Liu X, Marengere LE, Koch CA, Pawson T (1993) The v-Src SH3 domain binds phosphatidylinositol 3'-kinase. Mol. Cell. Biol. 13, 5225-5232.

Los M, Schenk H, Hexel K, Baeuerle PA, Droge W, Schulze-Osthoff K (1995a) IL-2 gene expression and NF-kappa B activation through $\mathrm{CD} 28$ requires reactive oxygen production by 5-lipoxygenase. EMBO J. 14, 3731-3740.

Los M, Stroh C, Janicke RU, Engels IH, Schulze-Osthoff K (2001) Caspases: more than just killers? Trends Immunol. 22, 31-34.

Los M, Van de Craen M, Penning LC, Schenk H, Westendorp M, Baeuerle PA, Droge W, Krammer PH, Fiers W, Schulze-Osthoff K (1995b) Requirement of an ICE/CED-3 protease for Fas/APO-1-mediated apoptosis. Nature 375, 81-83.

Luo Z, Fujio Y, Kureishi Y, Rudic RD, Daumerie G, Fulton D, Sessa WC, Walsh K (2000) Acute modulation of endothelial Akt/PKB activity alters nitric oxide-dependent vasomotor activity in vivo. J. Clin. Invest. 106, 493-499.

Luo J, Manning BD, Cantley LC (2003) Targeting the PI3K-Akt pathway in human cancer: rationale and promise. Cancer Cell 4, 257-262.

Maddika S, Ande SR, Panigrahi S, Paranjothy T, Weglarczyk K, Zuse A, Eshraghi M, Manda KD, Wiechec E, Los M (2007) Cell survival, cell death and cell cycle pathways are interconnected: implications for cancer therapy. Drug Resist. Updat. 10, 13-29.

Maddika S, Booy EP, Johar D, Gibson SB, Ghavami S, Los M (2005) Cancer-specific toxicity of apoptin is independent of death receptors but involves the loss of mitochondrial membrane potential and the release of mitochondrial celldeath mediators by a Nur77-dependent pathway. J. Cell Sci. 118, 4485-4493.

Maddika S, Mendoza FJ, Hauff K, Zamzow CR, Paranjothy T, Los M (2006) Cancer-selective therapy of the future: apoptin and its mechanism of action. Cancer Biol. Ther. 5, 10-19.

Marte BM, Downward J (1997) PKB/Akt: connecting phosphoinositide 3-kinase to cell survival and beyond. Trends Biochem. Sci. 22, 355-358.

Nimbalkar D, Henry MK, Quelle FW (2003) Cytokine activation of phosphoinositide 3-kinase sensitizes hematopoietic cells to cisplatin-induced death. Cancer Res. 63, 1034-1039.

Pekarsky Y, Hallas C, Palamarchuk A, Koval A, Bullrich F, Hirata Y, Bichi R, Letofsky J, Croce CM (2001) Akt phosphorylates and regulates the orphan nuclear receptor Nur77. Proc. Natl. Acad. Sci. USA 98, 3690-3694.

Pelengaris S, Khan M, Evan G (2002a) c-MYC: more than just a matter of life and death. Nat. Rev. Cancer 2, 764-776.

Pelengaris S, Khan M, Evan GI (2002b) Suppression of Myc-induced apoptosis in beta cells exposes multiple oncogenic properties of Myc and triggers carcinogenic progression. Cell 109, 321-334.

Pleiman CM, Hertz WM, Cambier JC (1994) Activation of phosphatidylinositol-3' kinase by Src-family kinase SH3 binding to the p85 subunit. Science 263, 1609-1612.

Poon IK, Oro C, Dias MM, Zhang J, Jans DA (2005a) Apoptin nuclear accumulation is modulated by a CRM1-recognized nuclear export signal that is active in normal but not in tumor cells. Cancer Res. 65, 7059-7064.

Poon IK, Oro C, Dias MM, Zhang JP, Jans DA (2005b) A tumor cell-specific nuclear targeting signal within chicken anemia virus VP3/apoptin. J. Virol. 79, 1339-1341.

Prasad KV, Janssen O, Kapeller R, Raab M, Cantley LC, Rudd CE (1993) Src-homology 3 domain of protein kinase p59fyn mediates binding to phosphatidylinositol 3-kinase in T cells. Proc. Natl. Acad. Sci. USA 90, 7366-7370.

Rameh LE, Cantley LC (1999) The role of phosphoinositide 3-kinase lipid products in cell function. J. Biol. Chem. 274, 8347-8350.

Rohn JL, Zhang YH, Aalbers RI, Otto N, Den Hertog J, Henriquez NV, Van De Velde CJ, Kuppen PJ, Mumberg D, Donner 
P, Noteborn MH (2002) A tumor-specific kinase activity regulates the viral death protein Apoptin. J. Biol. Chem. 277, 50820-50827.

Shiraishi I, Melendez J, Ahn Y, Skavdahl M, Murphy E, Welch S, Schaefer E, Walsh K, Rosenzweig A, Torella D, Nurzynska D, Kajstura J, Leri A, Anversa P, Sussman MA (2004) Nuclear targeting of Akt enhances kinase activity and survival of cardiomyocytes. Circ. Res. 94, 884-891.

Song G, Ouyang G, Bao S (2005) The activation of Akt/PKB signaling pathway and cell survival. J. Cell. Mol. Med. 9, $59-71$.

Stein RC (2001) Prospects for phosphoinositide 3-kinase inhibition as a cancer treatment. Endocr. Relat. Cancer 8, 237248.

Subramanian T, Chinnadurai G (2003) Pro-apoptotic activity of transiently expressed BCL-2 occurs independent of BAX and BAK. J. Cell. Biochem. 89, 1102-1114.

Teodoro JG, Heilman DW, Parker AE, Green MR (2004) The viral protein Apoptin associates with the anaphase-promoting complex to induce $\mathrm{G}_{2} / \mathrm{M}$ arrest and apoptosis in the absence of p53. Genes Dev. 18, 1952-1957.

Trotman LC, Alimonti A, Scaglioni PP, Koutcher JA, Cordon-Cardo C, Pandolfi PP (2006) Identification of a tumour suppressor network opposing nuclear Akt function. Nature 441, 523-527.

Vanhaesebroeck B, Alessi DR (2000) The PI3K-PDK1 connection: more than just a road to PKB. Biochem. J. 346 (Part 3 ), 561-576.

Vanhaesebroeck B, Waterfield MD (1999) Signaling by distinct classes of phosphoinositide 3-kinases. Exp. Cell Res. 253, 239-254.

Vivanco I, Sawyers CL (2002) The phosphatidylinositol 3-Kinase AKT pathway in human cancer. Nat. Rev. Cancer 2, 489-501.

Workman P (2004) Inhibiting the phosphoinositide 3-kinase pathway for cancer treatment. Biochem. Soc. Trans. 32, 393396.

Zheng Y, Bagrodia S, Cerione RA (1994) Activation of phosphoinositide 3-kinase activity by Cdc42Hs binding to p85. J. Biol. Chem. 269, 18727-18730. 